\title{
Cardiac tissue oxidative stress and inflammation after vitamin D administrations in high fat- diet induced obese rats
}

\author{
Mahdieh Abbasalizad Farhangi ${ }^{1 *}$ (D), Ghazaleh Nameni ${ }^{2}$, Ghazaleh Hajiluian ${ }^{3}$ and Mehran Mesgari-Abbasi ${ }^{1}$
}

\begin{abstract}
Background: Obesity is associated with numerous metabolic and inflammatory disorders. The current study was aimed to evaluate the effects of vitamin D administration on the markers of oxidative stress and inflammation in the cardiac tissue of high-fat diet induced obese rats.

Methods: In the beginning of the study, 40 male Wistar rats were divided into two groups: normal diet (ND) and high fat diet (HFD) for 16 weeks; then each group subdivided into two groups including: ND, ND + vitamin D, HFD and HFD + vitamin D. Vitamin D supplementation was done for 5 weeks at $500 \mathrm{lU} / \mathrm{kg}$ dosage. Tumor necrosis factor (TNF)-a concentration and markers of oxidative stress including glutathione peroxidase (GPx), superoxide dismutase (SOD), malondialdehyde (MDA) and catalase (CAT) concentrations in the cardiac tissue and serum concentrations of lipids in rats were determined using ELISA kits and spectrophotometry methods respectively.

Results: According to our results, GPx activity in ND and ND + vitamin D group was significantly higher compared with HFD group. Similarly, SOD activity was also significantly increased in ND + vitamin D group compared with ND and HFD groups. Moreover, vitamin D administration, significantly reduced catalase activity in ND + vitamin D and HFD + vitamin D groups $(P<0.05)$. TNF-a concentration in heart tissue in ND + vitamin D group significantly reduced compared with ND group. Cardiac tissue MDA concentration in baseline or after vitamin D administration did not changed significantly.
\end{abstract}

Conclusion: Vitamin D improved cardiac oxidative stress and inflammatory markers in HFD induced obese rats. Further studies in human models are needed to further confirm the use of this nutrient in daily clinical practice.

Keywords: Vitamin D, Cardiac tissue, Oxidative stress, Obesity, Inflammation

\section{Background}

The prevalence of obesity is increasing alarmingly worldwide and is a major health problem as a main leading cause of morbidity and mortality [1]. According to the final report of World Health Organization (WHO) in 2008 more than 1.4 billion of adults were overweight and over 200 million men and approximately 300 million women were obese [2]. The increasing prevalence of

\footnotetext{
* Correspondence: abbasalizad_m@yahoo.com

${ }^{1}$ Drug Applied Research Center, Nutrition Research Center, Department of Community Nutrition, Tabriz University of Medical Sciences, Attar Neyshabouri Street, Tabriz, Iran

Full list of author information is available at the end of the article
}

overweight and obesity has been defined as a global epidemic [3], which consumption of high fat diet (HFD) is one of the main reasons for this break-out $[4,5]$. Experimental studies indicated a linear relationship between the amount of fat intake and weight gain in humans and animal models [6]. In conjunction with its increasing prevalenece, obesity is associated with numerous healthrelated comorbidities including diabetes, insulin resistance, cardiovascular events and some types of cancers [5]. Among the pathologicaly responsible factors, oxidative stress, defined as an imbalance between tissue free radicals, reactive oxygen species (ROS) and antioxidants, is involved in the etiology of obesity-related pathologic 
conditions [1, 7]. Obesity, reduces antioxidant enzymes activity includes catalase, glutathione peroxidase (GPx) and glutathione reductase (GR) [1]. High fat diet, is a potent inducer of oxidative stress by altering oxygen metabolism. The fatty deposits as a consequence of high fat diet are vulnerable to suffering oxygen reactions; if the production of these ROS exceeds antioxidant system capacity of the cells, the lipid peroxidation occurs and the lipid peroxidation directly contributes in developing atherosclerosis [8]. The incidence of atherosclerosis or other comorbidities of cardiovascular system is due to oxidative- stress induced endothelial damage and vascular hypertrophy, platelet adhesions and atherosclerotic plaques formation [9]. Moroever, it has been suggested that obesity-induced dyslipidemia leads to tissue damage via oxidative modifications of lipids, protein glycation and glucose auto-oxidation and production of lipid peroxidation metabolits and the dyslipidemia predicts the CVD severity in obese patients [10-12]. Because of the high prevalnec of cardiovascualr disease due to obesity it is important to develop interventional and therapeutic strategies conquering the cardiovascular disaese morbidity in obese individuals [13]. From clinical point of view, the dietary interventions are useful in moderating the inflammatory biomarkers of cardiovascular disease; in the study by Neale et al. [14], the role of healthy dietary patterns in CRP reduction as a main classic cardiovascular risk factor has been indicated. Other studies also reported similar results [15]. However, it will be worth to investigate that which kind of dietary interventions will possibly reduce the markers of oxidative damage and inflammation in patients with cardiac events.

Tissue damage induced by free radicals is thought to be an important factor in the pathogenesis of obesity and obesity related disorders [16]. Measuring the antioxidant defense system in the cardiac tissue is a potent predictor of cardiovascular injury in metabolic disease. In the numerous models of CVD, including congestive heart failure or coronary artery disease, the tissue antioxidant system fails to work and as a consequence, oxygen derived free radicals are increased four-fold and their concentration in the cardiac tissue predicts the severity of heart failure [17]. Elevation of oxidative stress markers and ROS products in the cardiac tissue, leads to direct oxidative damage of cellular components [18].

Vitamin $\mathrm{D}$ as a nutrient contained in natural foods, after intake, requires skin exposure to ultraviolet B $(290-315 \mathrm{~nm})$ radiation and a series of sequential biochemical reactions occurring in the liver and kidneys to convert 7-dehydrocholesterol into a bio-functional form of vitamin D, which is called vitamin D3 or calcitriol (1,25-dihydroxycholecalciferol) [19].

Although vitamin D is classically well-known for its role in growth and remodeling of bone, recent studies have identified a much broader spectrum of its activity. It is now well recognized that vitamin $\mathrm{D}$, and particularly its active form calcitriol, is an important hormone playing a crucial role in human homeostasis [20]. In 1993, Wiseman first demonstrated that vitamin $\mathrm{D}$ is a potent antioxidant vitamin, preventing iron-dependent lipid peroxidation in the cell membrane and acting similar to the cancer drug Tamoxifen [21]. Since then, many studies have conducted to better identify the therapeutic antioxidant roles of vitamin $\mathrm{D}$ [22]. It has been shown that vitamin D deficinecy is a potential contributor of cardiovascular deaths. In the LURIC study, as a follow-up of the 3258 participants, patients with severe and moderate vitamin D deficiency were 1.8 to 2.5 times more likely to death from cardiovascular disease compared with patients with normal vitamin D concentrations [23]. In a vitamin D deficient animal model induced by vitamin $\mathrm{D}$ deficient diet, vitamin $\mathrm{D}$ deficiency increased arterial blood pressure and promoted vascular oxidative stress in rats [24] and was associated with promotion of atrial fibrillation in post-operative patients undergoing coronary artery bypass graft (CABG) surgery [25]. However, considering our review of literature, the role of vitamin D therapy in health of CVD is a neglected factor.

Moreover, according to above mentioned introduction, it seems that evaluating the role of vitamin D on improving the oxidative damage and inflammation in cardiac tissue has two major benefits; firstly, the results, possibly, will add an important information regarding vitamin $\mathrm{D}$ as a factor protecting from oxidative stress and inflammation in cardiac tissue and cardiovascular system that would be easy to add this nutrient in daily clinical practice, and secondly, because of the direct association of markers of oxidative stress and inflammatory parameters with cardiovascular events in human, the results of the current study, could be applicable for using the markers of oxidative stress and inflammation as valuable diagnostic markers in cardiovascular events especially because numerous recent studies reached several debate about using diffused inflammatory markers such as CRP in clinical working; several reports are available showing little or no improvement in the prediction of risk of cardiac events with the addition of CRP to conventional risk factors of cardiovascular disease $[26,27]$. Therefore in the current experimental model, we aimed to evaluate the role of vitamin D administration in the cardiac tissue oxidative stress and tumor necrosis factor (TNF) - $\alpha$ concentrations in highfat diet induced obese rats.

\section{Methods}

The design of study has been mentioned in our previous report [28-30]. Therefore, the characteristics of animals and procedures are reported here briefly. 


\section{Animals, diets and experimental procedures}

Forty male Wistar rats weighted 200-220 g were purchased from the Pasteur institute animal care center (Karaj, Iran). The animals were housed five in each cage under standard conditions (light on from 07:00 AM to 07:00 PM and constant temperature of $25 \pm 2{ }^{\circ} \mathrm{C}$ ) with ad libitum access to food and water. Animal experiments were conducted in conformity with the National Institutes of Health ethical guidelines for the care and use of laboratory animals (NIH; Publication No. 85-23, revised 1985) and approved by the veterinary ethics committee of the Tabriz university of medical sciences (Registration number: TBZMED.REC.1395.532). After a week of acclimatization and feeding a standard laboratory chow diet, rats were randomly assigned into 2 groups $(n=20$, each group): either normal diet (ND) or high fat diet (HFD). ND contained 10\% fat, 30\% protein and $60 \%$ carbohydrate and HFD contained $59 \%$ fat, $11 \%$ protein and 30\% carbohydrate [31]. After four months of receiving ND and HFD, groups randomized in to two subgroups including ND, ND + vitamin D, HFD and HFD + vitamin D, which supplemented with vitamin D or Migliol (Sigma Adrich, USA) $500 \mathrm{IU} / \mathrm{kg} / \mathrm{d}$ by oral gavage alongside with their prior diets for 5 weeks. Moreover, body weight was weekly measured by scale (PAND Industries, px3000, $5 \mathrm{~kg} \pm 1 \mathrm{~g}$ ) while food intake was monitored 3 times a week.

\section{Preparation of blood and heart samples}

After an overnight fasting, the rats were anesthetized with Ketamin $(6.6 \mathrm{mg} / \mathrm{kg})$ and Xylazine $(0.3 \mathrm{mg} / \mathrm{kg})$ intra peritoneally. Blood samples were obtained from cardiac puncture and centrifuged at $10000 \mathrm{~g}$ at $4{ }^{\circ} \mathrm{C}$ for $20 \mathrm{~min}$; sera were separated and stored in an ultra-low temperature freezer (Jal Tajhiz Production, Iran) at $-80{ }^{\circ} \mathrm{C}$ until assay. Finally, after rats were sacrificed by decapitation, their heart samples were removed and its hemisphere was collected and immediately stored at $-80{ }^{\circ} \mathrm{C}$ until further use.

\section{ELISA}

Before and after vitamin D supplementation, serum measurement was performed to determine initial and terminal vitamin D level by individual enzyme-linked immunosorbent assay kit (ELISA) (Eastbiopharm, Zhejiang, China) according to the manufacturer's instructions. Heart tissues were homogenized in phosphate buffered saline (PBS) and centrifuged at $10000 \mathrm{~g}$ at $4{ }^{\circ} \mathrm{C}$ for $20 \mathrm{~min}$, and clear supernatants were collected and the total protein concentration was measured by protein assay kit (Pars Azmun, Tehran, Karaj). TNF- $\alpha$ concentration in the supernatants were determined using ELISA (Hangzhou Eastbiopharm, Zhejiang, China).

\section{Measurement of oxidative stress}

The cardiac tissue homogenates were used for determination of glutathione peroxidase (GPx), superoxide dismutase (SOD), malondialdehyde (MDA) and catalase by spectrophotometry in accordance with the protocol provided with the assay kits.

\section{Glutathione peroxidase and superoxide dismutase assessment}

GPx activity was measured according to Paglia and Valentine method [32] using Ransel, Randox kit (United Kingdom). SOD was assayed by a spectrophotometric method based on the inhibition of a superoxide-induced reduced nicotinamide adenine dinucleotide (NADH) oxidation according to Paoletti et al. method [33] by using Ransod, Randox kit (United Kingdom).

\section{Malondialdehyde assessment}

Malondialdehyde (MDA) levels were measured using the thiobarbituric acid reactive substances (TBARS) method [34].

\section{Catalase assessment}

The activities of catalase enzyme were measured according to Hugo aebi method [35].

\section{Statistical analysis}

All statistical analyses were performed using SPSS software, version 16. Kolmogorov-Smirnov test was performed for normality of the distributions of variables. Data are expressed as the mean \pm SD. The data were analyzed using one-way analysis of variance (ANOVA) followed by post hoc Tukey's tests and paired sample $t$-test for comparisons between multiple groups and two groups. $P<0.05$ was considered as statistically significant.

\section{Results \\ Changes in food intake and body weight during the study period}

Changes in food intake of animals during the study period have been shown in Fig. 1. Food intake of animals was gradually increased until the administration of vitamin D and this increase was meaningful in all of study groups. However, after vitamin D administration, in ND and HFD groups, food intake decreased significantly $(P<0.001)$. Accordingly, the baseline body weights were similar among the different groups (Table 1). However, there was a significant difference in body weights of all treated groups at the end of the study $(P=0.001)$. Moreover, Post-hoc analysis showed that in the intergroup comparisons of body weight, HFD led to a significant weight gain versus ND group $(P=0.001)$. 


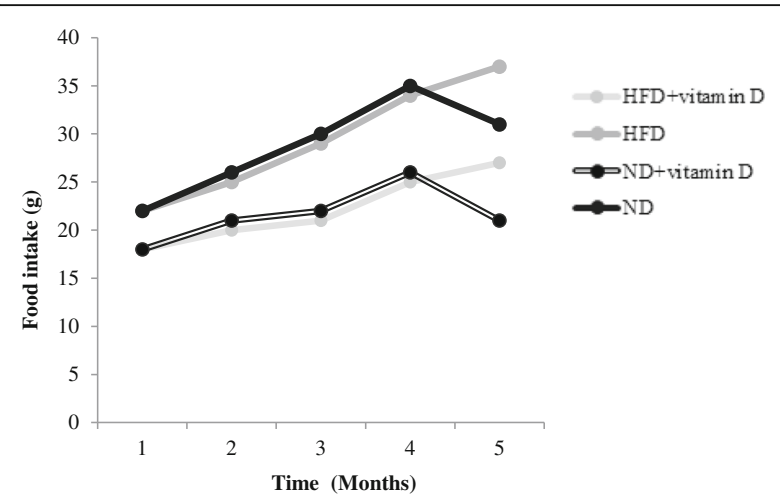

Fig. 1 Food intake of studied groups during study period. HFD, high fat diet; ND, normal diet. A reduction in food intake after vitamin $D$ administrations has been occurred in both vitamin D-administered groups $(P<0.001)$

\section{Changes in serum vitamin D concentrations during the study period}

Baseline concentrations of vitamin $\mathrm{D}$ was not significantly different between groups $(P=0.50)$. As expected, vitamin $\mathrm{D}$ administrations led to a marked increase in serum vitamin $\mathrm{D}$ concentrations in $\mathrm{ND}+$ vitamin $\mathrm{D}$ and HFD + vitamin D groups $(P=0.001)$; whereas, serum vitamin $D$ concentrations in HFD and ND groups reduced significantly (Table 2 ).

\section{Changes in serum LDL, HDL, TC and TG concentrations of rats after vitamin $D$ administration}

Table 3 presents the effects of vitamin D administration on serum concentrations of low density lipoprotein (LDL), high density lipoprotein (HDL), total cholesterol (TC) and triglyceride (TG) concentrations. Serum LDL concentration after vitamin $\mathrm{D}$ administration significantly reduced in ND + vitamin D and HFD + vitamin D compared with ND and HFD groups $(P<0.05)$. Serum TG and TC were also reduced in HFD+ vitamin D group compared with HFD group $(P<0.05)$. No significant change in serum HDL was observed.

Table 1 Changes in body weight of rats

\begin{tabular}{lllll}
\hline Groups & $1^{\text {th }}$ week & $16^{\text {th }}$ week & $21^{\text {st }}$ week & ${ }^{\dagger} P$ value \\
\hline ND & $218.9 \pm 10.83$ & $276.1 \pm 26.72$ & $288.9 \pm 29.80$ & 0.001 \\
ND + Vitamin D & $224.6 \pm 22.09$ & $278 \pm 27.38$ & $255.9 \pm 26.90$ & 0.001 \\
HFD & $218.7 \pm 13.27$ & $403.2 \pm 4.13$ & $425.4 \pm 3.71$ & 0.001 \\
HFD + Vitamin D & $224.9 \pm 13.77$ & $399.8 \pm 8.7$ & $380.6 \pm 7.80$ & 0.001 \\
${ }^{*} P$ value & 0.69 & 0.001 & 0.001 & \\
\hline
\end{tabular}

Data are expressed as means \pm SD. Statistical differences between groups were assessed by one-way ANOVA followed by Tukey's test for Post Hoc analysis. Intra group comparisons of body weight were performed by repeated measure analysis. ${ }^{\dagger} P$ value and ${ }^{\ddagger} P$ value indicated intra group and inter group differences, respectively. $P<0.05$ was considered as statistically significant
Table 2 Vitamin D concentrations in study groups

\begin{tabular}{lllll}
\hline Groups & $\begin{array}{l}16^{\text {th }} \\
\text { week }\end{array}$ & $\begin{array}{l}21^{\text {th }} \\
\text { week }\end{array}$ & $\begin{array}{l}\text { Mean } \\
\text { difference }\end{array}$ & $\begin{array}{l}{ }^{\dagger} P \\
\text { value }\end{array}$ \\
\hline ND & $47.50 \pm 7.32$ & $36.30 \pm 7.74$ & $-11.20 \pm 1$ & 0.001 \\
ND + Vitamin D & $54.87 \pm 11.53$ & $119.09 \pm 26.01$ & $64.22 \pm 7.8$ & 0.001 \\
HFD & $51.19 \pm 11.16$ & $37.70 \pm 11.53$ & $-13.49 \pm 4.25$ & 0.01 \\
HFD + Vitamin D & $53.24 \pm 14.11$ & $123.70 \pm 39.39$ & $70.46 \pm 12.85$ & 0.001 \\
${ }^{\ddagger} P$ value & 0.50 & 0.001 & & \\
\hline
\end{tabular}

Data are expressed as means \pm SD. Statistical differences between groups were assessed by one-way ANOVA followed by Tukey's test for Post Hoc analysis. Intra group comparisons of serum vitamin $D$ was performed by paired $t$-test analysis. ${ }^{\dagger} P$ value and ${ }^{\ddagger} P$ value indicated intra group and inter group differences, respectively. $P<0.05$ was considered as statistically significant

\section{Changes in the TNF- $a$ concentration and markers of oxi- dative stress in the heart tissue}

According to our results (Fig. 2), vitamin D administration, significantly reduced catalase activity in ND + vitamin D and HFD + vitamin D groups $(P<0.05)$. GPx activity in $\mathrm{ND}$ and ND + vitamin D group was significantly higher compared with HFD group. Although no difference between ND versus ND+ vitamin D or HFD versus HFD + vitamin D groups in terms of cardiac GPx activity was observed. SOD activity significantly increased in $\mathrm{ND}+$ vitamin D group compared with ND and HFD groups. Also, cardiac tissue TNF- $\alpha$ concentration in $\mathrm{ND}+$ vitamin D group significantly reduced compared with ND group. No difference in MDA concentration between groups has been observed.

\section{Discussion}

In the present study, we showed that vitamin D administration for 5 weeks has potential cardio-protective effects by modulating biomarkers of inflammation and oxidative stress in cardiac tissue and serum lipids in high-fat diet induced obese rats. According to our results, weight was gradually increased in all groups but HFD group significantly gained more body weight than other groups. Moreover, the present study showed that vitamin $\mathrm{D}$ administration protects against cardiac oxidative stress as shown by increased SOD and

Table 3 Changes in serum lipids in study groups

\begin{tabular}{lllll}
\hline Groups & $\begin{array}{l}\mathrm{LDL}-\mathrm{C} \\
(\mathrm{mg} / \mathrm{dl})\end{array}$ & $\begin{array}{l}\mathrm{HDL}-\mathrm{C} \\
(\mathrm{mg} / \mathrm{dl})\end{array}$ & $\begin{array}{l}\text { TG } \\
(\mathrm{mg} / \mathrm{dl})\end{array}$ & $\begin{array}{l}\mathrm{TC} \\
(\mathrm{mg} / \mathrm{dl})\end{array}$ \\
\hline $\mathrm{ND}$ & $27.82 \pm 5.88$ & $30.08 \pm 7.54$ & $41.60 \pm 5.01$ & $74.02 \pm 3.15$ \\
$\mathrm{ND}+$ & $19.56 \pm 5.39$ & $27.64 \pm 7.16$ & $50.56 \pm 5.02$ & $70.32 \pm 3.28$ \\
Vitamin D & & & & \\
$\mathrm{HFD}$ & $23.96 \pm 5.81$ & $42.50 \pm 7.73$ & $54.02 \pm 10.51$ & $73.38 \pm 7.68$ \\
HFD + & $19.04 \pm 4.63$ & $33.72 \pm 9.43$ & $46.14 \pm 5.32$ & $65.00 \pm 2.47$ \\
$\begin{array}{l}\text { Vitamin D } \\
{ }^{\dagger} \text { value }\end{array}$ & 0.05 & 0.79 & 0.043 & 0.034 \\
\hline
\end{tabular}

Data are expressed as means \pm SD. Statistical differences between groups were assessed by one-way ANOVA followed by Tukey's test for Post Hoc analysis. ${ }^{\dagger} P$ value indicated inter group differences. $P<0.05$ was considered as statistically significant 

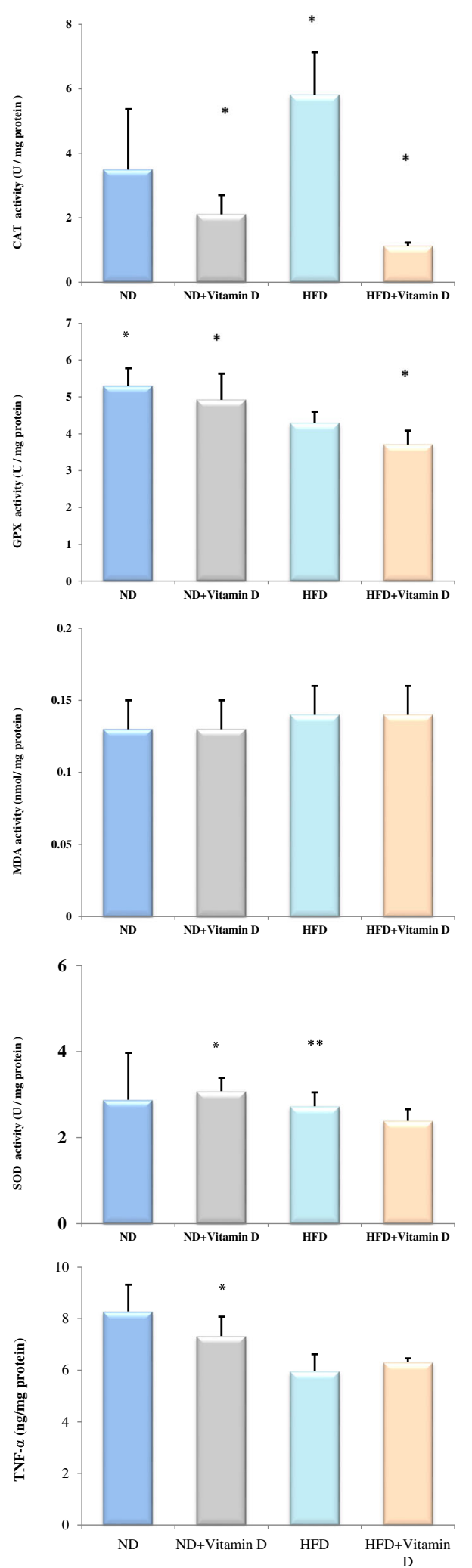

Fig. 2 Effects of vitamin D administration on parameters of oxidative stress and TNF-a concentration in heart tissue. * Significant difference between groups $(P<0.05)$
GPx activity and reduced cardiac tissue inflammation by reducing TNF- $\alpha$ concentration in high fat diet induced obese rats.

The obesity models induced by high fat diet in rats has many common points with human obesity and numerous studies have revealed that antioxidants act as obesity regulators in high fat diet induced obese rats [9]. Obesity is associated with reduced antioxidant defense system in different body organs including heart tissue; in the current research high fat receiving groups had partially increased MDA and reduced antioxidant enzymes activity although these differences were not statistically significant; similarly, several previous reports also confirmed that HFD leads to reduction in serum and cardiac tissue oxidative defense $[9,10,36]$. The antioxidant enzymes like SOD, GPx and catalase scavenge reactive oxygen species and stop their formation; SOD and GPx activities as chief scavengers of anion superoxide $\left(\mathrm{O}^{2-}\right)$ increase after vitamin D administration. In our results, HFD receiving groups had higher baseline catalase activity compared with ND receiving groups and the catalase concentration reduced after vitamin $\mathrm{D}$ administration. On the other side, baseline GPx activity was lower among obese rats. Similar to our results, elevated SOD activity was also reported in HFD induced obese rats in the Ansari et al. study [9]. In fact, this finding can be explained by compensatory adaptation of organism to oxidative stress in high fat diet induced obesity. Numerous previous reports have suggested that change in the antioxidant defense system and oxidative stress markers in the body is tissue specific; in other word, as previously suggested by Noyan et al. different body organs might response to oxidative stress selectively by decrease or increase in the concentrations of markers of oxidative stress [37]; increased catalase activity of heart tissue in obese rats, may be an important adaptive response to conditions of increased oxidative stress in the obesity and the biological availability of superoxide anion radicals and hydrogen peroxide in adipose tissue. The increased catalase activity reflects the increased superoxide anion radicals and hydrogen peroxide as catalase decomposes hydrogen peroxide to water and oxygen [38]. In the current work, vitamin D exerted its therapeutic antioxidant roles via decreasing the elevated concentrations of SOD in vitamin D treated rats.

The antioxidant potential of vitamin $\mathrm{D}$ is attributed to reduced lipid peroxidation, suppressed nicotinamide adenine dinucleotide phosphate (NADPH) enzyme expression and inhibition of the advanced glycation end products (AGEs) accumulation in the aortic tissue [39, 40]. It has been shown that vitamin $D$, as an antioxidant molecule, is able to decrease the endothelial impairment after $\mathrm{H}_{2} \mathrm{O}_{2}$ mediated stress, preventing extrinsic caspase cascade activation, switching on MEKs/ERKs/SIRT-1 axis and inhibiting the ROS release [41, 42]. Therefore, vitamin $\mathrm{D}$ has potent influence on cardiac endothelial system by affecting oxidative stress system of endothelial cells. 
Vitamin D treatment increased SOD activity in ND+ vitamin D group versus ND group; whereas, in HFD + vitamin D group versus HFD group no significant change was observed. This conflict result can be explained by this fact that increased sequestering of the vitamin D occurs in adipose tissue of obese animals and human [43]. As previously reported, for each $1 \mathrm{~kg} / \mathrm{m}^{2}$ increase in body mass index (BMI) in human, an estimated decrease of $0.74 \mathrm{nmol} / \mathrm{L}$ of serum vitamin $\mathrm{D}$ has been observed [44] and the vitamin $\mathrm{D}$ trapping potential of adipose tissue in obesity limits the functional role of this vitamin by reducing its concentrations in the blood.

Vitamin D exerted its anti-inflammatory actions via reducing cardiac TNF- $\alpha$ concentrations in the current work. Similarly, in the study by Al-Rasheed et al. the effects of vitamin D on TNF- $\alpha$ expressions in rat's heart had been examined and the results showed that vitamin $\mathrm{D}$ protects against cardiac hypertrophy via reducing TNF- $\alpha$ expression by inhibiting NF-kB/p65 signaling pathway [45]. Accordingly, the antagonistic role of vitamin D against TNF- $\alpha$ expression has been confirmed in other studies establishing that vitamin D targets TNF- $\alpha$ pathway to reduce its concentrations in different tissue and organs $[46,47]$.

Accordingly, vitamin D modified the altered lipid abnormalities and reduced serum LDL, TG and TC concentrations. In fact, dyslipidemia is a very common feature of obesity and a high fat diet is a useful method to induce a model of dyslipidemia in animals or human [48-50]. Therapeutic roles of vitamin D in modification of lipid abnormalities which had been previously confirmed by numerous studies $[51,52]$ further clarifies the strong cardio-protective potential of this steroid vitamin in treatment of numerous obesity-related disorders.

\section{Conclusion}

The current work revealed that vitamin D ameliorates oxidative stress by increasing the antioxidant enzymes activity and reduces TNF- $\alpha$ concentration in the cardiac tissue of high-fat diet induced obese rats. Therefore the results of the current study further clarify the cardio-protective potential of vitamin D in obesity. Further studies in human models with favorable findings could finally suggest the use of this vitamin in daily clinical practice.

\footnotetext{
Abbreviations

AGEs: Advanced glycation end-products; ANOVA: Analysis of variance; CAD: Coronary artery disease; CAT: Catalase; CVD: Cardiovascular disease; GPx: Glutathione peroxidase; HDL: High density lipoprotein cholesterol; LDL: Low density lipoprotein cholesterol; MDA: Malondialdehyde; NADH: Nicotinamide adenine dinucleotide; SOD: Superoxide dismutase; TBARS: Thiobarbituric acid reactive substances; TC: Total cholesterol; TNF-a: Tumor necrosis factor-a
}

Acknowledgements

We thank all of the study participants.

\section{Funding}

This research has been funded by a grant from Drug Applied Research Center Tabriz University of Medical Sciences.

\section{Availability of data and materials}

The datasets used and/or analyzed during the current study available from the corresponding author on reasonable request.

\section{Authors' contributions}

All authors have read and approved the manuscript; MAF was the main researcher, designed the project, wrote the manuscript and performed the statistical analysis, revised the manuscript and supervised the project. GN and $\mathrm{GH}$ were involved in data collection and acquisition of data and MMA was involved in laboratory works and experimental design of the work.

\section{Competing interests}

The authors declare that they have no competing interests.

\section{Consent for publication}

Not applicable.

\section{Ethics approval}

Animal experiments were conducted in conformity with the National Institutes of Health ethical guidelines for the care and use of laboratory animals (NIH; Publication No. 85-23, revised 1985) and approved by the veterinary ethics committee of the Tabriz university of medical sciences (Registration number: TBZMED.REC.1395.532).

\section{Publisher's Note}

Springer Nature remains neutral with regard to jurisdictional claims in published maps and institutional affiliations.

\section{Author details}

${ }^{1}$ Drug Applied Research Center, Nutrition Research Center, Department of Community Nutrition, Tabriz University of Medical Sciences, Attar

Neyshabouri Street, Tabriz, Iran. ${ }^{2}$ Student Research Committee, Neuroscience Research Center, Tabriz University of Medical Sciences, Tabriz, Iran. ${ }^{3}$ Nutrition Research Center, Department of Community Nutrition, Tabriz University of Medical Sciences, Tabriz, Iran.

Received: 21 April 2017 Accepted: 14 June 2017

Published online: 19 June 2017

\section{References}

1. Fernandez-Sanchez A, Madrigal-Santillan E, Bautista M, Esquivel-Soto J, Morales-González A, Esquivel-Chirino C, et al. Inflammation, oxidative stress, obesity. Int J Mol Sci. 2011:12(5):3117-32.

2. Miller AA, Spencer SJ. Obesity and neuroinflammation: a pathway to cognitive impairment. Brain Behav Imunol. 2014:42:10-21.

3. Ng M, Fleming T, Robinson M, Thomson B, Graetz N, Margono C. Global, regional, and national prevalence of overweight and obesity in children and adults during 1980-2013: a systematic analysis for the global burden of disease study 2013. Lancet. 2014;384(9945):766-81.

4. Komaki A, Karimi SA, Salehi I, Sarihi A, Shahidi S, Zarei M. The treatment combination of vitamins $E$ and $C$ and astaxanthin prevents high-fat diet induced memory deficits in rats. Pharacol Biochem. 2015;131(88):98-103.

5. Gortmaker SL, Swinburn BA, Levy D, Carter R, Mabry PL, Finegood DT. Changing the future of obesity: science, policy, and action. Lancet. 2011; 378(9793):838-47

6. Hariri N, Thibault L. High-fat diet-induced obesity in animal models. NRR. 2010;23(2):270-99.

7. Khaki Khatibi F, Yaghoubi A, Zarghami N, Rahbani M, Babaie H. Evaluation of hs-CRP, antioxidant markers and MDA in patients of coronary artery disease (CAD) containing non-smokers and non-diabetics. J Cardiovasc Thorac Res. 2011:2(4):13-8.

8. Khan N, Naz L, Yasmeen G. Obesity: an independent risk factor systemic oxidative stress. Park J Pharm Sci. 2006:19:62-9.

9. Ansari JA, Bhandari U, Pillai KK, Haque SE. Effect of rosuvastatin on obesityinduced cardiac oxidative stress in Wistar rats-a preliminary study. Indian J Exp Biol. 2012;50(3):216-22. 
10. Olorunnisola OS, Bradley G, Afolayan AJ. Protective effect of T. violacea rhizome extract against hypercholesterolemia-induced oxidative stress in Wistar rats. Molecules. 2012;17(5):6033-45.

11. Pezeshkian M, Darbin A, Rashidi MR, Vatankhah A, Golmohammadi Z Afrasiabi A, et al. The effect of atherogenic diet with or without enzyme inhibitors on the incidence and progress of atherosclerosis in rabbits. J Cardiovasc Thorac Res. 2011;3(1):7-10.

12. Sokhanvar S, Mazaki RRS, Mousavinasab N, Golmohammadi Z. The association between serum lipoprotein (a) and other cardiac risk factors with the severity of coronary artery disease. J Cardiovasc Thorac Res. 2011;3(1):35-9.

13. Sharifi MH, Eftekhari MH, Ostovan MA, Rezaianazadeh A. Effects of a therapeutic lifestyle change diet and supplementation with Q10 plus Lcarnitine on quality of life in patients with myocardial infarction: a randomized clinical trial. J Cardiovasc Thorac Res. 2017;9(1):21-8.

14. Neale EP, Batterham MJ, Tapsell LC. Consumption of a healthy dietary pattern results in significant reductions in C-reactive protein levels in adults: a meta-analysis. Nutr Res. 2016;36(5):391-401.

15. Farhangi MA, Najafi M, Jafarabadi MA, Jahangiry L. Mediterranean dietary quality index and dietary phytochemical index among patients candidate for coronary artery bypass grafting (CABG) surgery. BMC Cardiovasc Disord. 2017:17:114-22.

16. Noyan T, Balaharog R, Kömürog U. The oxidant and antioxidant effects of 25-hydroxyvitamin D3 in liver, kidney and heart tissues of diabetic rats. Clin Exp Med. 2005;5:31-6.

17. Tardif JC, Bourassa MG. Use of antioxidants in patients with heart failure. Antioxidants and cardiovascular disease. USA: Springer Science \& Business Media; 2012. p. 213.

18. Rodrigo R, Libuy M, Feliú F, Hasson D. The protective effect of lipoic acid on selected cardiovascular diseases caused by age-related oxidative stress. Oxid Med Cell Long. 2015; 2015:Article ID 313021.

19. Borel P, Caillaud D, Cano NJ. Vitamin D bioavailability: state of the art. Crit Rev Food Sci Nutr. 2015:55:1193-205.

20. Walentowicz-Sadłecka M. W.P. Sadłecki P, Grabiec M. The role of vitamin D in the carcinogenesis of breast and ovarian cancer. Ginekol Pol. 2013;84(4):305-8.

21. Wiseman $H$. Vitamin $D$ is a membrane antioxidant Ability to inhibit irondependent lipid peroxidation in liposomes compared to cholesterol, ergosterol and tamoxifen and relevance to anticancer action. FEBS Lett 1993;326:285-288

22. Ke CY, Yang FL, Wu WT, Chung CH, Lee RP, Yang WT, et al. Vitamin D3 reduces tissue damage and oxidative stress caused by exhaustive exercise. Int J Med Sci. 2016;13(2):147-53.

23. Murr C, Pilz S, Grammer TB, Kleber ME, Meinitzer A, Boehm BO. Vitamin D deficiency parallels inflammation and immune activation, the Ludwigshafen risk and cardiovascular health (LURIC) study. Clin Chem Lab Med. 2012;50(12):2205-12.

24. Argacha JF, Egrise D, Pochet S, Fontaine D, Lefort A, Libert F, et al. Vitamin D deficiency-induced hypertension is associated with vascular oxidative stress and altered heart gene expression. J Cardiovasc Pharmacol. 2011;58(1):65-71.

25. Gode S, Aksu T, Demirel A, Sunbul M, Gul M, Bakır I, et al. Effect of vitamin D deficiency on the development of postoperative atrial fibrillation in coronary artery bypass patients. J Cardiovasc Thorac Res. 2016;8(4):140-6.

26. Danesh J, Wheeler JG, Hirschfield GM, Eda S, Eiriksdottir G, Rumley A, et al. C-reactive protein and other circulating markers of inflammation in the prediction of coronary heart disease. N Engl J Med. 2004;350(14):1387-97.

27. Barbero U, D'Ascenzo F, Nijhoff F, Moretti C, Biondi-Zoccai G, Mennuni M, et al. Assessing risk in patients with stable coronary disease: when should we intensify care and follow-Up? results from a meta-analysis of observational studies of the COURAGE and FAME Era. Scientifica (Cairo). 2016; 2016: 3769152.

28. Hajiluian G, Nameni G, Shahabi P, Mesgari-Abbasi M, Sadigh-Eteghad S, Farhangi MA. Vitamin D administration, cognitive function, BBB permeability and neuroinflammatory factors in high-fat diet-induced obese rats. Int J Obes (Lond). 2017; 41: 639-644.

29. Nameni G, Hajiluian G, Shahabi P, Farhangi MA, Mesgari-Abbasi M, Hemmati MR. The impact of vitamin D supplementation on neurodegeneration, TNFa concentration in hypothalamus, and CSF-to-plasma ratio of insulin in high-fat-diet-induced obese rats. J Mol Neurosci. 2016;61(2):247-55.

30. Nameni G, Farhangi MA, Hajilouian G, Shahabi P, Mesgari-Abbasi M. Insulin deficiency: a possible link between obesity and cognitive function. Int J Dev Neurosci. 2017;59:15-20.

31. Sobesky JL, Barrientos RM, Henning S, Thompson BM, Weber MD, Watkins LR. High-fat diet consumption disrupts memory and primes elevations in hippocampal IL-1 $\beta$, an effect that can be prevented with dietary reversal or IL-1 receptor antagonism. Brain Behav Immun. 2014;42:22-32.

32. Erion JR, Wosiski-Kuhn M, Dey A, Hao S, Davis CL, Pollock NK. Obesity elicits interleukin 1-mediated deficits in hippocampal synaptic plasticity. J Neurosci. 2014;34(7):2618-31

33. Boitard C, Cavaroc A, Sauvant J, Aubert A, Castanon N, Layé S. Impairment of hippocampal-dependent memory induced by juvenile high-fat diet intake is associated with enhanced hippocampal inflammation in rats. Brain Behav Immun. 2014:40:9-17.

34. Pozzi F, Frajese GV, Frajese G. Vitamin D (Calcifediol) supplementation modulates NGF and BDNF and improves memory function in postmenopausal women: a pilot study. Endocrinol. 2013:1-11.

35. Latimer CS, Brewer LD, Searcy JL, Chen K-C, Popović J, Kraner SD. Vitamin D prevents cognitive decline and enhances hippocampal synaptic function in aging rats. Proc Natl Acad Sci. 2014;111(41):E4359-E66.

36. Noeman SA, Hamooda HE, Baalash AA. Biochemical study of oxidative stress markers in the liver, kidney and heart of high fat diet induced obesity in rats. Diabetol Metab Syn. 2011;3(1):17-25.

37. Hünkar T, Aktan F, Ceylan A, Karasu C. Effects of cod liver oil on tissue antioxidant pathways in normal and streptozotocin- diabetic rats (the ADIC study group). Cell Biochem Funct. 2002;20:297-302.

38. Maritim AC, Sanders RA, Watkins JB. Diabetes, oxidative stress and antioxidants: a review. J Biochem Mol Toxicol. 2003;17:24-38.

39. Tarcin O, Yavuz DG, Ozben B, Telli A, Ogunc AV, Yuksel M. Effect of vitamin $D$ deficiency and replacement on endothelial function in asymptomatic subjects. J Clin Endocrinol Metab. 2009:94:4023-30.

40. Hirata M, Serizawa K, Aizawa K, Yogo K, Tashiro Y, Takeda S. 22-Oxacalcitriol prevents progression of endothelial dysfunction through antioxidative effects in rats with type 2 diabetes and early-stage nephropathy. Nephrol Dial Transplant. 2013;28:1166-74.

41. Polidoro L, Properzi G, Marampon F, Gravina GL, Festuccia C, Di Cesare E. Vitamin D protects human endothelial cells from $\mathrm{H}(2) \mathrm{O}(2)$ oxidant injury through the Mek/Erk- Sirt1 axis activation. J Cardiovasc Transl Res. 2013:6:221-31.

42. Uberti F, Lattuada D, Morsanuto V, Nava U, Bolis G, Vacca G. Vitamin D protects human endothelial cells from oxidative stress through the autophagic and survival pathways. J Clin Endocrinol Metab. 2014;99:1367-74.

43. Wortsman J, Matsuoka LY, Chen TC, Lu Z, Holick MF. Decreased bioavailability of vitamin D in obesity. Am J Clin Nutr. 2007;72:690-3.

44. McGill A-T, Stewart JM, Lithander FE, Strik CM, Poppitt SD. Relationships of low serum vitamin D3 with anthropometry and markers of the metabolic syndrome and diabetes in overweight and obesity. Nutr J. 2008;7:4-9.

45. Al-Rasheed NM, Al-Rasheed NM, Bassiouni YA, Hasan $\mathrm{H}, \mathrm{Al}-\mathrm{Amin} \mathrm{MA}, \mathrm{Al}$ Ajmi $\mathrm{HN}$, et al. Vitamin D attenuates pro-inflammatory TNF-a cytokine expression by inhibiting NF-kB/p65 signaling in hypertrophied rat hearts. J Physiol Biochem. 2015;71(2):289-99.

46. Zhu Y, Mahon BD, Froicu M, Cantorn MT. Calcium and 1 alpha,25dihydroxyvitamin D target the TNF-alpha pathway to suppress experimental inflammatory bowel disease. Eur J Immunol. 2005:35:217-24.

47. Moller S, Laigaard F, Olgaard K, Hemmingsen C. Effect of 1, 25-dihydroxyvitamin D3 in experimental sepsis. Int J Med Sci. 2007:4(4):190-5.

48. Farhangi MA, Keshavarz SA, Eshraghian M, Ostadrahimi A, Saboor-Yaraghi AA. White blood cell count in women: relation to inflammatory biomarkers, haematological profiles, visceral adiposity, and other cardiovascular risk factors. J Health Popul Nutr. 2013;31(1):58-64.

49. Buettner R, Schölmerich J, Bollheimer LC. High-fat diets: modeling the metabolic disorders of human obesity in rodents. Obesity. 2007;15(4):798-808.

50. McGill AT, Stewart JM, Lithander FE, Strik CM, Poppitt SD. Relationships of low serum vitamin D 3 with anthropometry and markers of the metabolic syndrome and diabetes in overweight and obesity. Nutr J. 2008;7(1):4.

51. Asemi Z, Hashemi T, Karamali M, Samimi M, Esmaillzadeh A. Effects of vitamin D supplementation on glucose metabolism, lipid concentrations, inflammation, and oxidative stress in gestational diabetes: a double-blind randomized controlled clinical trial. Am J Clinical Nutr. 2013;98(6):1425-32.

52. Nagpal J, Pande JN, Bhartia A. A double-blind, randomized, placebocontrolled trial of the short-term effect of vitamin D3 supplementation on insulin sensitivity in apparently healthy, middle-aged, centrally obese men. Diab Med. 2009;26(1):19-27. 